\title{
The inhibitory effects of NKX3.1 on IGF-1R expression and its signalling pathway in human prostatic carcinoma PC3 cells
}

\author{
Peng-Ju Zhang ${ }^{1}$, Xiao-Yan $\mathrm{Hu}^{1}$, Chun-Yan Liu ${ }^{1}$, Zhao-Bo Chen ${ }^{1}, \mathrm{Na}-\mathrm{Na} \mathrm{Ni}{ }^{1}$, Yang $\mathrm{Yu}^{1}$, Li-Na Yang ${ }^{2}$, \\ Zhao-Qin Huang ${ }^{3}$, Qing-Wei Liu ${ }^{3}$ and An-Li Jiang ${ }^{1}$
}

\begin{abstract}
NKX3.1, which is a prostate-specific homeobox gene, plays an important role in prostate cancer and usually functions as a tumour suppressor gene. In this study, we investigated the inhibitory effect of NKX3.1 on insulin-like growth factor (IGF)-1R expression and its downstream signalling pathway in PC3 cells. PC3 cells were stably transfected with NKX3.1 expression plasmid (pcDNA3.1-NKX3.1) or vector plasmid (pcDNA3.1+). The IGF-IR mRNA and protein expression levels were assessed in PC3-NKX3.1 transfectants by reverse transcriptase-polymerase chain reaction (RT-PCR) and Western blotting. The expression and activation of IGF-1/IGF-1R downstream signalling targets were examined by Western blotting and luciferase reporter assay. The cells were subsequently treated with relevant concentrations of IGF-1. The effect of IGF-1 on cell growth was examined by 3-(4,5)-dimethylthiahiazo(-z-y1)-3, 5-diphenytetrazoliumromide (MTT) assay and flow cytometry analysis. A significant suppression of IGF-1R mRNA and protein expression was observed after forced expression of NKX3.1 in PC3 cells. Correspondingly, the forced expression of NKX3.1 decreased IGF-1-induced phosphorylation of extracellular signal-regulated kinase $1 / 2$ (ERK1/2) and protein kinase B (AKT) and activation of the Elk-1 transcription factor and downregulated the expression of the downstream target genes $c$-fos and $c y c l i n D 1$. Furthermore, the forced expression of NKX3.1 inhibited IGF-1-induced cell growth. In conclusion, NKX3.1 could downregulate IGF-1R expression and could inhibit IGF-1R-mediated mitogen-activated protein kinase (MAPK)/ERK and AKT signalling pathways, which might partially leads to the inhibition of IGF-1-induced cell growth. This study provides new insights into the molecular mechanisms that NKX3.1 exerts against prostate cancer and ultimately expands the scope of alternative approaches in advanced prostate cancer therapy. Asian Journal of Andrology (2012) 14, 493-498; doi:10.1038/aja.2011.158; published online 19 December 2011
\end{abstract}

Keywords: IGF-1; IGF-1R; NKX3.1; prostate cancer

\section{INTRODUCTION}

Prostate cancer is one of the most common cancers and continues to be a major cause of death in ageing men. ${ }^{1}$ Although androgen ablation therapy is effective in its initial stages, prostate cancer often progresses to a hormone-resistant state characterized by a high proliferation rate and strong propensity to metastases after a period of remission. ${ }^{2,3}$ Progression of these tumours is facilitated by growth factors that activate critical signalling cascades, thereby promoting prostate cancer cell growth, survival and migration. ${ }^{4}$ Among these events, the insulin-like growth factor (IGF) signalling pathway contributes a major role. ${ }^{5-8}$ IGF-1 binding to its receptor (IGF-1R) results in tyrosine kinase activation and stimulation of downstream signalling pathways, including Ras/mitogen-activated protein kinase (MAPK) and phosphatidylinositol 3'-kinase/AKT. These signalling pathways are strongly implicated in prostate cancer progression. ${ }^{9-13}$ IGF-1R, an important transmembrane IGF receptor, acts as a crucial component in this growth signal transduction. Several studies ${ }^{14-16}$ have reported that IGF-1R expression is elevated in metastatic prostate cancer, and the progression of hormone resistance is associated with increased IGF-1R expression. Thus, the inhibition of the activity of IGF-1R may provide an alternative approach for prostate cancer treatment.

NKX3.1 is a prostate-specific homeobox gene that is thought to play an important role in the normal development of the prostate and carcinogenesis. In humans, NKX3.1 maps to the p21 region of chromosome 8 , which undergoes allelic deletion in approximately $80 \%$ of prostate cancers. ${ }^{17-21}$ Loss of NKX3.1 protein expression has been observed in approximately $40 \%$ of human prostate cancers and in approximately $20 \%$ of prostatic intraepithelial neoplasia lesions. Therefore, NKX3.1 is often referred to as a candidate tumour suppressor gene. Our previous gene expression profile analysis revealed that NKX3.1 could decrease IGF-1R mRNA expression. ${ }^{22}$ In this study, we examined the effect of NKX3.1 on IGF-1R and IGF-1/IGF-1R signalling in PC3 cells. Next, we determined whether NKX3.1 could influence the responsiveness of PC3 cells to IGF-1 stimulation in different NKX3.1 expression conditions. The findings of this report

${ }^{1}$ Institution of Biochemistry and Molecular Biology, Medical School of Shandong University, Jinan 250012, China; ${ }^{2}$ The People's Hospital of Zhangqiu City, Zhangqiu 250200, China and ${ }^{3}$ Department of Radiology, Shandong Provincial Hospital, Jinan 250021, China Correspondence: Professor AL Jiang (jianganli@sdu.edu.cn) and Dr QW Liu (liuqingwei6@yahoo.com.cn)

Received: 5 August 2011; Revised: 2 September 2011; Accepted: 27 September 2011; Published online: 19 December 2011 
are significant for understanding the molecular mechanisms by which NKX3.1 exerts its anti-tumour activity.

\section{MATERIALS AND METHODS}

\section{Cell culture and treatment}

The stable PC3 transfectants with NKX3.1 eukaryotic expression plasmid pcDNA3.1-NKX3.1 or pcDNA3.1 (+) vector, designated PC3NKX3.1 or PC3-mock, respectively, were established in our previous study. $^{22}$ The cells were maintained in RPMI-1640 medium (Gibco; Invitrogen, Carlsbad, CA, USA), which was supplemented with $10 \%$ foetal bovine serum, 100 units per $\mathrm{ml}$ penicillin and $100 \mathrm{mg} \mathrm{ml}^{-1}$ streptomycin at $37{ }^{\circ} \mathrm{C}$ with $5 \% \mathrm{CO}_{2}$. For IGF-1 treatment, the cells were plated and cultured in complete RPMI-1640 overnight. After the cells were rendered quiescent by overnight culture in serum-free RPMI-1640, the cells were incubated with different concentrations of IGF-1 at the time points indicated in the figure legends (IGF-1 was replenished $48 \mathrm{~h}$ after the beginning of treatment). IGF-1 was purchased from Sigma-Aldrich (St Louis, MO, USA).

\section{Reverse transcriptase-polymerase chain reaction (RT-PCR)}

Total RNA was isolated using TRIzol Reagent (Invitrogen). The cDNA of the given mRNA was synthesized with M-MuLV reverse transcriptase (Promega, Madison, WI, USA) in the presence of random hexamer primers. The primers used for PCR were:

$I G F-1 R$ forward primer F: 5' -ACCCGGAGTACTTCAGCGCT-3' reverse primer R: 5' -CACAGAAGCTTCGTTGAGAA-3'

$\beta$-actin forward primer F: $5^{\prime}$-GTGGGGCGCCCAGGCACCAC-3' reverse primer R: 5'-CTCCTTAATGTCACGCACGATTT-3'

PCR conditions consisted of an initial denaturation at $94{ }^{\circ} \mathrm{C}$ for 3 min and 28 cycles of amplification with denaturation at $94^{\circ} \mathrm{C}$ for $30 \mathrm{~s}$, primer annealing at $58{ }^{\circ} \mathrm{C}(\beta$-actin $)$ or $52{ }^{\circ} \mathrm{C}(I G F-1 R)$ for $30 \mathrm{~s}$, and primer extension at $72{ }^{\circ} \mathrm{C}$ for $30 \mathrm{~s}$. The final primer extension was performed at $72{ }^{\circ} \mathrm{C}$ for $6 \mathrm{~min}$. The products were identified by $1.5 \%$ agarose gel electrophoresis.

\section{Western blotting analysis}

Western blotting was performed as previously described. ${ }^{22,23}$ Wholecell lysates were prepared using lysis buffer (containing $50 \mathrm{mmol} \mathrm{l}^{-1}$ Tris-Cl, pH 8.0, $150 \mathrm{~m} \mathrm{~mol}^{-1} \mathrm{NaCl}, 0.1 \% \mathrm{SDS}, 1 \% \mathrm{NP}-40$ and $100 \mu \mathrm{g} \mathrm{ml}^{-1}$ PMSF). Fifty microgrammes of each sample were processed for SDS-PAGE and electrophoretic transfer to a polyvinylidene fluoride membrane. Total IGF-IR was determined using a phosphorylation-independent IGF-1R $\beta$-subunit polyclonal antibody (Santa Cruz Biotech Inc., Santa Cruz, CA, USA). Phosphorylation of AKT was detected with polyclonal antibodies directed against phosphoSer473 from Cell Signaling Technology (Beverley, MA, USA). Activation of extracellular signal-regulated kinases (ERKs) was detected by blotting with ERK1+ERK2 (phospho T185/ T202+Y204/Y187) polyclonal antibody (Abcam, Cambridge, MA, USA). Cyclin D1 and c-fos polyclonal antibodies were purchased from Santa Cruz Biotech Inc. All primary antibodies were detected with horseradish peroxidase-conjugated anti-rabbit or anti-mouse antibodies (Santa Cruz Biotech Inc.). Relative protein levels were calculated compared to $\beta$-actin as the standard. Immunoblots were detected using an ECL kit (Santa Cruz Biotech Inc.) and were visualized after exposure to X-ray film.

\section{Construction of the luciferase reporter plasmid}

A synthetic dual-copy tandem Elk-1 consensus binding DNA sequence (70 bp) was generated as shown below. In the sense strand, the underlined sequences at $5^{\prime}$ and $3^{\prime}$ ends were Hind III and Sac I sites, respectively.

(sense): 5'-AGCTTACTGTGAAAACAATTCCTGCATTTTGCAAAACTGTGAAAACAATTCCTGCATTTTGCAAAGAGCT-3'

(antisense): 5' -CTTTGCAAAATGCAGGAATTGTTTTCACAGTTTTGCAAAATGCAGGAATTGTTTTCACAGTA- ${ }^{\prime}$

The double-stranded sequences were generated by annealing equimolar complementary oligonucleotides in sterilized water at $95^{\circ} \mathrm{C}$ for $10 \mathrm{~min}$, which were subsequently cooled down to room temperature slowly and inserted upstream of the luciferase reporter in the pGL4.23 [luc2/minP] vector (Promega). The construct was designated pGL4Elk-1, which was confirmed by restriction enzyme digestion and sequence analysis.

\section{Transient transfection and luciferase assays}

Cell transfections were performed using FuGENE ${ }^{R}$ HD (Roche, Indianapolis, IN, USA) according to the manufacturer's instructions. The cells were grown in 24-well plates to $90 \%$ confluence and transfected for $24 \mathrm{~h}$ in serum-free RPMI-1640 medium with $0.5 \mu \mathrm{g}$ of pGL4-Elk-1 or parental vector and with $0.02 \mu \mathrm{g}$ of pRL-TK Renilla luciferase vector (Promega) as an internal control. Next, the cells were treated with $100 \mathrm{ng} \mathrm{ml}^{-1}$ of IGF-1. After they were incubated for another $24 \mathrm{~h}$, the cells were harvested for luciferase assays using the Dual Luciferase Assay System (Promega). The relative activity of luciferase was calculated and expressed as the ratio of firefly luciferase (M1) and Renilla luciferase (M2) activities. The experiments were performed three times in duplicate.

\section{3-(4,5)-dimethylthiahiazo(-z-y1)-3,5-diphenytetrazoliumromide (MTT) colorimetric assay}

MTT analysis was performed as described previously. ${ }^{22}$ In brief, the cells were treated with or without IGF-1 for the indicated times. Next, MTT $\left(5 \mathrm{mg} \mathrm{ml}^{-1}\right)$ was added to the wells. After incubation for another $4 \mathrm{~h}$, the media in the wells was replaced with dimethylsulphoxide $(100 \mu \mathrm{l}$ per well). The plates were agitated at room temperature for $10 \mathrm{~min}$. The absorbance (value $A$ ) of every well at a wavelength of $570 \mathrm{~nm}$ against the background at $630 \mathrm{~nm}$ was read on an ELISA reader. The arithmetic mean absorbance of six wells for each group was calculated.

\section{Flow cytometry analysis}

After treatment with IGF-1 for $24 \mathrm{~h}$, the cells were washed with PBS twice, harvested by trypsinisation and fixed with cold $70 \%$ ethanol for $1 \mathrm{~h}$. Next, the cells were washed again with PBS and were incubated with $50 \mu \mathrm{g} \mathrm{ml}^{-1}$ of ribonuclease A (Roche) for $30 \mathrm{~min}$ at room temperature. Propidium iodide was added to the cell suspension at a final concentration of $50 \mu \mathrm{g} \mathrm{ml}^{-1}$ and incubated for $30 \mathrm{~min}$. Cells were then analysed by flow cytometry using a FACScan (Becton Dickinson, SanJose, CA, USA). The results were quantified by using the software CellQuest (Becton Dickinson).

\section{Data analysis}

All experiments were repeated at least three times. Values were given as mean \pm s.d. Data were analysed using SPSS 10.0 software (SPSS Inc., Chicago, IL, USA). Statistical significance was assessed by analysis of variance and the unpaired $t$-test. $P<0.05$ indicated a significant result.

\section{RESULTS}

NKX3.1 downregulates the expression of IGF-1R

Our previous gene expression profile analysis revealed that NKX3.1 could decrease the expression of IGF-1R mRNA. ${ }^{22}$ To investigate the effect of NKX3.1 on the IGF-1/IGF-1R system, IGF-1R expression was 


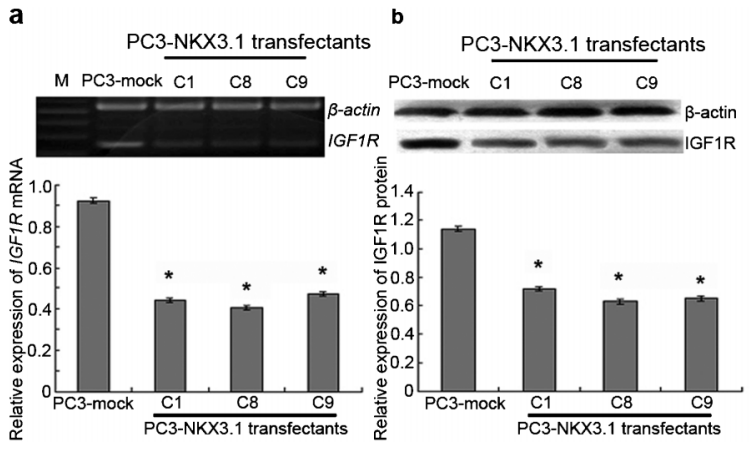

Figure 1 NKX3.1 inhibits the expression of IGF-1R. (a) RT-PCR to measure IGF-1R mRNA levels. (b) Western blotting to measure IGF-1R protein levels. PC3-mock cells were transfected with pcDNA3.1 (+) vector. PC3-NKX3.1 transfectants $\mathrm{C} 1, \mathrm{C} 8$ and $\mathrm{C} 9$ were stably transfected with pcDNA3.1-NKX3.1. $\beta$-actin was used as an equal loading control. The density of each band was quantified using the image software BandScan5.0, and the ratios of the bands were calculated and represented as relative expression levels. Each value represents the mean \pm s.d. of three independent experiments. $* P<0.05$, compared with relative expression of PC3-mock cells. IGF, insulin-like growth factor.

first determined at both the mRNA and protein levels using RT-PCR and Western blotting. The results showed that the IGF-1R mRNA level decreased by an average of $52.4 \%$ in PC3-NKX3.1 compared to the PC3-mock level (Figure 1a). As shown in Figure 1b, a similar decrease was also demonstrated at the IGF-1R protein level. These results suggested that restoring expression of NKX3.1 in PC3 cells could effectively downregulate IGF-1R expression.

\section{NKX3.1 suppresses IGF-1R downstream signalling pathways}

The downstream signal of IGF-1R contains two principle pathways: MAPK/ERK and AKT pathways. Several changes in protein expression which correlated with these downstream of IGF-1R signalling were detected using Western blotting analysis. As shown in Figure $2 \mathbf{a}$ and $\mathbf{b}$, IGF-1 treatment resulted in significant elevation of phosphorylated AKT and ERK1/2 levels both in PC3-mock and PC3-NKX3.1 cells. However, the increase of phosphorylated AKT and ERK1/2 was obviously lower $(P<0.05)$ in PC3-NKX3.1 than in PC3-mock, suggesting that NKX3.1 could inhibit IGF-1-induced phosphorylation of AKT and ERK1/2. The stimulated expressions of the target genes cyclin $D 1$ and $c$-fos by IGF-1-induced pathways were inhibited from $126 \%$ (in PC3-mock) to 51\% (in PC3-NKX3.1) and from 84\% (in PC3-mock) to $52 \%$ (in PC3-NKX3.1), respectively (Figure $2 \mathrm{c}$ and d). Furthermore, as is evident from Figure 2e, the luciferase reporter assay demonstrated that the activation of Elk-1 was also dramatically attenuated from $52 \%$ (in PC3-mock) to 26\% (in PC3-NKX3.1). Taken together, these data suggested that NKX3.1 inhibited IGF-1/IGF-1R downstream pathways, including the MAPK/ERK pathway and the AKT pathway.

\section{NKX3.1 suppresses IGF-1-induced cell growth}

As a known mitogenic factor, IGF-1 induces cell proliferation via binding to its receptor IGF-1R, which is a key part of the IGF-1/ IGF-1R signalling pathway. Therefore, the effect of NKX3.1 on IGF1 -induced cell growth was further evaluated. PC3-mock cells and PC3NKX3.1 cells (clone 8) were treated with the indicated dose of IGF-1 for the indicated time (Figure $\mathbf{3} \mathbf{a}$ and $\mathbf{b}$ ). Data from the MTT assay demonstrated that IGF-1 could induce both PC3-mock and PC3NKX3.1 cell growth in a dose- (Figure 3a) and time-related (Figure 3b) manners. However, the effect of IGF-1 on PC3-NKX3.1 cells was obviously weaker than the effect on PC3-mock cells. Next, we
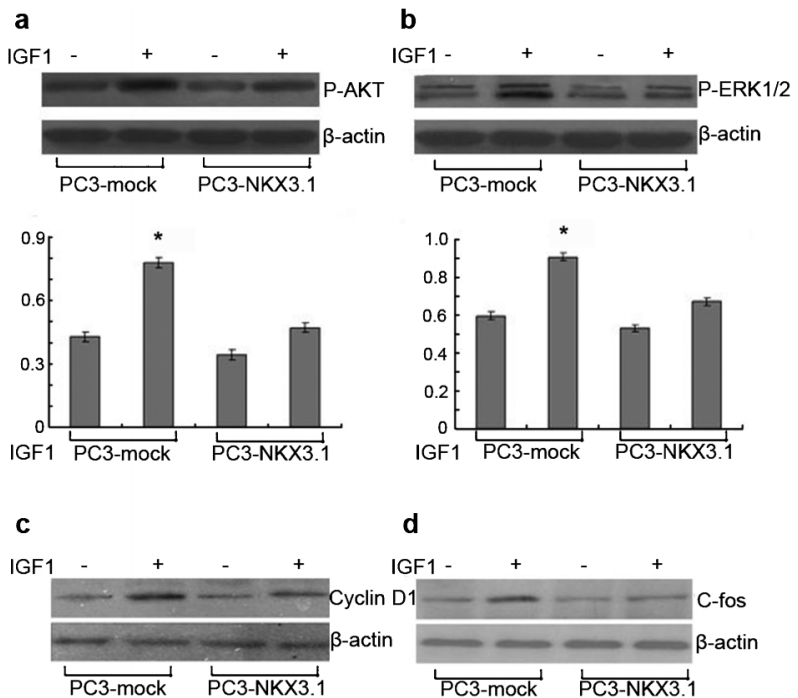

d
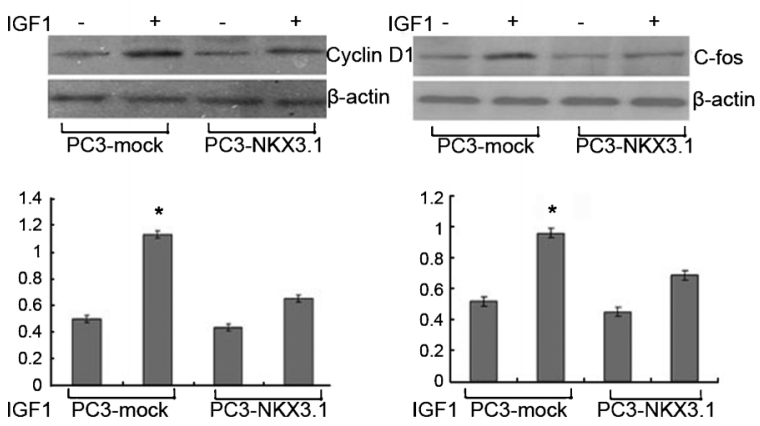

$\mathbf{e}$

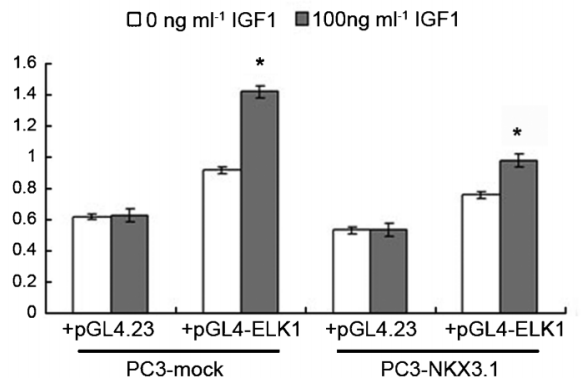

Figure 2 NKX3.1 suppresses IGF-1R downstream signalling pathways. (a-d) Western blotting to measure the phosphorylation of AKT (a) and ERK1/2 (b) and the expression of cyclin D1(c) and c-fos (d). The cells were starved in serum-free medium for $24 \mathrm{~h}$. Next, IGF-1 (100 $\mathrm{ng} \mathrm{ml}^{-1}$ ) was added to stimulate cells for 15 min (a, b), 24 h (c) and 2 h (d). After treatment, cell lysis and immunoblotting was performed. $\beta$-actin was used as an equal loading control. The density of each band was quantified using the image software BandScan5.0, and the ratios of bands were calculated and represented as relative expression levels. Each value represents the mean \pm s.d., $n=3$. $* P<0.05$, compared with that without IGF-1 treatment. (e) Luciferase reporter assay to measure the transcriptional activity of Elk-1. The cells were transfected with pGL4-Elk-1 or parental vector pGL4.23 for $24 \mathrm{~h}$ in serum-free medium and were treated with $100 \mathrm{ng} \mathrm{ml}^{-1}$ IGF-1 for another $24 \mathrm{~h}$. Next, the cells were harvested for the dual-luciferase assay. The pRL-TK vector was used to correct for transfection efficiency. The results were expressed as the relative luciferase activities (M1/M2). The data were represented as mean \pm s.d., $n=6$. $* P<0.05$, compared with that without IGF-1 treatment. PC3-mock cells were transfected with pcDNA3.1 (+) vector. PC3-NKX3.1 cells were stably transfected with pcDNA3.1-NKX3.1. IGF, insulin-like growth factor.

treated PC3-mock and PC3-NKX3.1 transfectants (clones 1, 8 and 9) with $100 \mathrm{ng} \mathrm{ml}^{-1}$ IGF-1 for $24 \mathrm{~h}$. The results showed that IGF-1 dramatically increased cell growth in PC3-mock cells by $55.0 \%$ compared to cell growth without IGF-1 treatment. However, NKX3.1 suppressed the IGF-1-induced cell growth in PC3-NKX3.1 cells, 


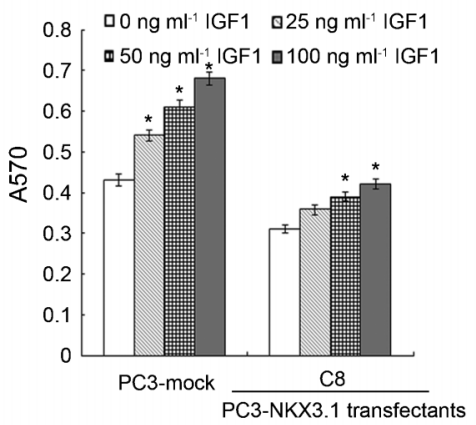

b

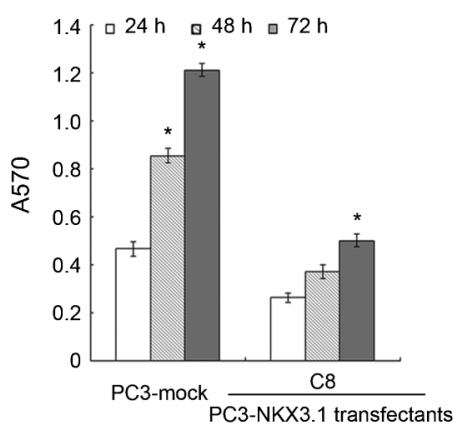

c

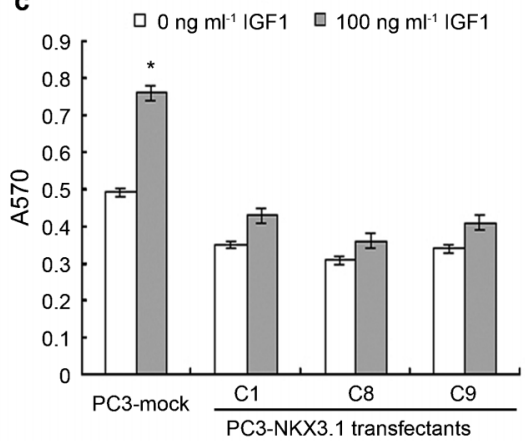

d
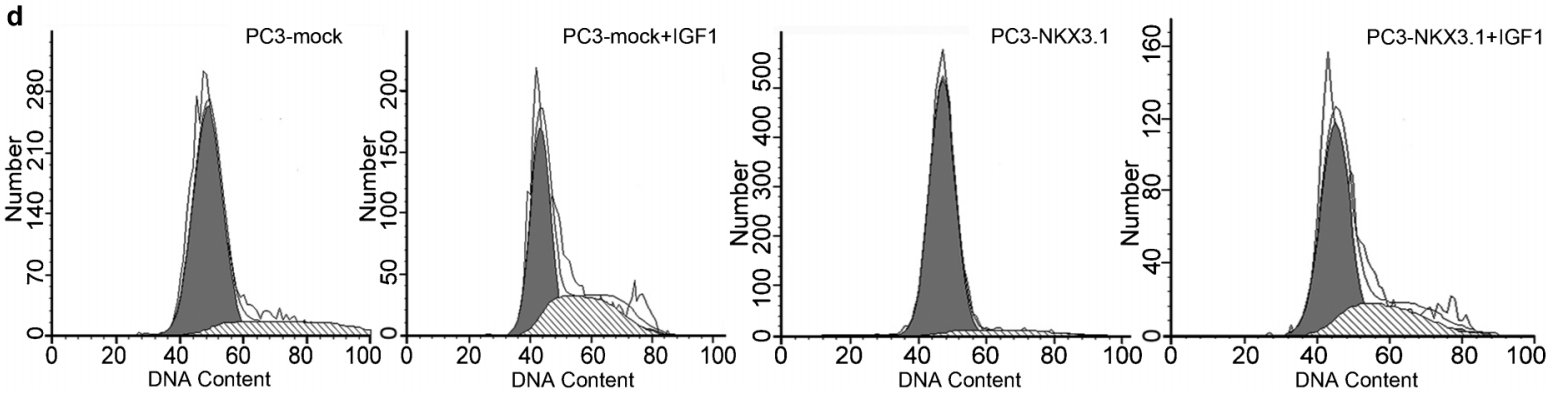

Figure 3 NKX3.1 inhibits IGF-1-induced cell growth. (a-c) MTT assay to measure PC3 cell proliferation. Cells were starved in serum-free medium for $24 \mathrm{~h}$. Next, cells were treated with the indicated concentrations of IGF-1 for $24 \mathrm{~h}$ (a), with $100 \mathrm{ng} \mathrm{ml}{ }^{-1} \mathrm{IGF}-1$ for the indicated times (b) and $100 \mathrm{ng} \mathrm{ml}^{-1}$ IGF-1 for 24 h (c). PC3-mock cells were transfected with pcDNA3.1 (+) vector. PC3-NKX3.1 transfectants C1, C8 and C9 were stably transfected with pcDNA3.1-NKX3.1. The data are expressed as mean \pm s.d. of three independent experiments in six replicates. $* P<0.05$, compared with that without IGF-1treatment. (d) Flow cytometry to analyse the cell cycle. Cells were treated as described above. After treatment with $100 \mathrm{ng} \mathrm{ml}^{-1} \mathrm{IGF}-1$ for $24 \mathrm{~h}$, the cells were collected and stained with propidium iodide for cell cycle analysis. The data are representative of three separate experiments. IGF, insulin-like growth factor; MTT, 3-(4,5)-dimethylthiahiazo(-z-y1)-3,5-diphenytetrazoliumromide.

where the cell growth was increased by only 19.3\% (Figure 3c). Results from flow cytometry indicated that $85.5 \%$ of PC3-mock cells were arrested in the $\mathrm{G}_{0} / \mathrm{G}_{1}$ phase without IGF-1 treatment, while $50.8 \%$ of PC3-mock cells were observed in the $G_{0} / G_{1}$ phase with IGF-1 treatment. In contrast, the percentage of PC3-NKX3.1 cells observed in the $\mathrm{G}_{0} / \mathrm{G}_{1}$ phase decreased from $92.4 \%$ to $73.2 \%$ after treatment with IGF1 (Figure 3d). All of these data suggested that forced expression of NKX3.1 could blunt the responsiveness of PC3 cells to IGF-1 stimulation. Thus, NKX3.1 could inhibit IGF-1-induced cell proliferation.

\section{DISCUSSION}

Prostate cancer, which initially responds well to androgen ablation, invariably progresses to treatment resistance. Upregulated growth and survival signalling via the IGF-1/IGF-1R system has been suggested to play a key role in malignant transformation of prostate cancer cells. ${ }^{24}$ Several studies have shown that IGF binds to IGF-1R in prostate cancer cells to stimulate cancer cell growth and facilitate the development of bone metastasis. ${ }^{15,16,25}$ IGF-1 increases proliferation of prostate cancer cells in vitro, whereas antisense-mediated inhibition of IGF-1R expression suppresses tumour growth in vivo and prevents prostate cancer cell invasiveness. ${ }^{14,26}$ In human prostate cancer cell xenografts, progression to androgen independence is associated with increased expression of both IGF-1R and IGF-1. ${ }^{9,12}$ Thus, the inhibition of IGF-1R actions may provide an optional approach for advanced prostate cancer treatment.

NKX3.1 is a putative prostate tumour suppressor that is expressed exclusively in the prostate, with its loss being involved in the initiation and progression of prostate cancer. ${ }^{21}$ Our previous study revealed that NKX3.1 could decrease IGF-1R mRNA levels in PC3 cells. ${ }^{22}$ In this study, we further investigated the effects of NKX3.1 on IGF-1R expression and in IGF-1/IGF-1R signalling pathways.
The expression of IGF-1R was first examined by RT-PCR and Western blotting in both PC3-mock cells and PC3-NKX3.1 transfectants. As a result, forced expression of NKX3.1 in PC3 cells did inhibit the expression of IGF-1R at both the mRNA and protein levels. NKX3.1 is proposed to be a nuclear transcriptional factor that preferentially binds the TAAGTA sequence ${ }^{27}$ to regulate the expression of its target gene. Two such NKX3.1-binding sites were identified in a $3.3-\mathrm{kb}$ sequence upstream of the $I G F-1 R$ gene with the MatInspector program. NKX3.1 might bind to these sites to regulate the expression of IGF-1R. However, further study is needed to reveal the details of this mechanism.

Subsequently, the expression and activation states of IGF-1R downstream signalling targets were examined by Western blotting and a luciferase reporter assay. Though multiple pathways concerning cell growth and survival are stimulated by the activation of the IGF-1R axis, the MAPK/ERK and AKT pathways play the most prominent roles. ${ }^{28,29}$ One important component of the MAPK/ERK pathway is ERK, which belongs to the MAPK subfamily. Once IGF-1R binds to its extracellular signals, the MAPK pathway will be activated through a kinase cascade, which results in phosphorylation of ERK1 and ERK2. Next, phosphorylated ERK1 and ERK2 translocate to the cell nucleus and recruit transcription factors, thereby stimulating cell proliferation. $^{28,29}$ Elk-1 is one such transcription factor and is a well-known substrate of ERK. ${ }^{30}$ Elk-1 regulates the transcription of immediateearly response genes, including c-fos, through serum response elements (SREs) within their promoters. ${ }^{31,32}$ In this report, the phosphorylation of ERK1/2 and the expression of c-fos were examined by Western blotting in aforementioned cells after treatment with IGF-1. The transcriptional activity of Elk-1 was analysed by a Luciferase reporter assay. As a result, forced expression of NKX3.1 in PC3 cells inhibited IGF-1-induced phosphorylation of ERK1/2, expression of 
c-fos and activation of Elk-1. Another known pathway regulated by IGF-1R is phosphatidylinositol $3^{\prime}$-kinase/AKT signalling. AKT is a major kinase that is known to activate many downstream targets, such as phospho-GSK-3 $\beta$. Cyclin D1 is a substrate of phospho-GSK-3 $\beta$ and is required for G1 cell cycle progression. In this study, the phosphorylation of AKT and the protein levels of cyclin D1 were also examined. The results demonstrated that NKX3.1 expression inhibited IGF-1-induced phosphorylation of AKT and cyclin D1 expression. All of these data indicated that forced expression of NKX3.1 in PC3 cells could inhibit the two major pathways of IGF-1R-mediated signalling.

IGF-1 functions as a potent mitogen to stimulate cell growth through an IGF-1R-mediated cell survival pathway. The effects mediated by IGF-I and IGF-1R interaction are dependent on the levels of IGF-1R expressed on the cell surface. As the number of receptors increases, so does the effect that IGF-1 exerts. ${ }^{33}$ Because IGF-1R expression and its downstream signalling were inhibited by forced expression of NKX3.1, the mitogenic response of PC3NKX3.1 cells to IGF-1 stimulation should have been altered. The cell growth was subsequently tested using an MTT assay and flow cytometry analysis. The results showed that forced expression of NKX3.1 could decrease the sensitivity of PC3 cells to IGF-1 stimulation. Meanwhile, our previous studies and other studies have shown that forced expression of NKX3.1 also resulted in reduced cell proliferation without IGF-1 stimulation in PC3 cells. ${ }^{22,34}$ These data indicated that besides the IGF-1/IGF-1R system, additional mechanisms might be involved in the anti-proliferation function of NKX3.

In summary, this study demonstrated that NKX3.1 could downregulate IGF-1R expression and inhibit its downstream signalling pathways, thereby inhibiting IGF-1-induced cell growth in PC3 cells. This work will enhance our knowledge regarding the mechanisms of NKX3.1 anti-proliferation against prostate cancer and will ultimately expand the scope of alternative approaches for advanced prostate cancer therapy.

\section{AUTHOR CONTRIBUTIONS}

PJZ assisted in the design of the study, carried out the cloning of reporter plasmid constructs, transfection studies, RT-PCR, MTT assay and Western blotting; and helped draft the manuscript. XYH assisted in the design of the study, participated in the sequence alignment and use of computer database; assisted in the construction of recombinant vectors; and helped draft the manuscript. CYL performed FCS and assisted with the transfection experiments. ZBC participated in maintenance of cell lines and performed luciferase reporter assays. NNN carried out the isolation of RNA and purification of plasmids. YY assisted with the RT-PCR and Western blotting. LNY carried out Western blot and assisted with the purification of plasmids. ZQH assisted with the maintenance of cell lines and the transfection experiments. QWL participated in the design of the study and assisted with the revising of the manuscript. ALJ participated in the design of the study and revision of the manuscript, helped draft the manuscript and assisted with the construction of recombinant vectors. All authors have read and approved the final manuscript.

\section{COMPETING FINANCIAL INTERESTS}

The authors declare that the research was conducted in the absence of any commercial or financial relationship that could be construed as a potential conflict of interest.

\section{ACKNOWLEDGMENTS}

This study was supported by the National Natural Science Foundation of China (Nos. 81071720 and 30900550), the Shandong Provincial Programmes for Science and Technology Development (No. 2009GG20002045) and the Natural Science Foundation of Shandong Province (No. ZR2009CQ034).

1 Jemal A, Siegel R, Xu J, Ward E. Cancer statistics, 2010. CA Cancer J Clin 2010; 60 277-300

2 Morgan C, Wagstaff J. Is there a role for ibandronate in the treatment of prostate cance patients with bony metastases?. Acta Oncol 2009; 48: 822-9. Review.

3 Armstrong AJ, Carducci MA. Advanced prostate cancer: the future. Can J Urol 2005 ; 12 (Suppl 2): 42-7.

4 Zhu ML, Kyprianou N. Androgen receptor and growth factor signaling cross-talk in prostate cancer cells. Endocr Relat Cancer 2008; 15: 841-9.

5 Pollak M. Insulin-like growth factor-related signaling and cancer development. Recent Results Cancer Res 2007; 174: 49-53.

6 LeRoith D, Roberts CT Jr. The insulin-like growth factor system and cancer. Cancer Lett 2003; 195: 127-37.

7 Papatsoris AG, Karamouzis MV, Papavassiliou AG. Novel insights into the implication of the IGF-1 network in prostate cancer. Trends $\mathrm{Mol}$ Med 2005; 11: 52-5.

8 Ryan CJ, Haqq CM, Simko J, Nonaka DF, Chan JM et al. Expression of insulin-like growth factor-1 receptor in local and metastatic prostate cancer. Urol Oncol2007; 25 $134-40$.

9 DiGiovanni J, Kiguchi K, Frijhoff A, Wilker E, Bol DK et al. Deregulated expression of insulin-like growth factor 1 in prostate epithelium leads to neoplasia in transgenic mice. Proc Natl Acad Sci USA 2000; 97: 3455-60.

10 Pollak M. Insulin-like growth factor physiology and cancer risk. Eur J Cancer 2000 36: 1224-8.

11 Chan JM, Stampfer MJ, Ma J, Gann P, Gaziano JM et al. Insulin-like growth factor-I (IGF-I) and IGF binding protein-3 as predictors of advanced-stage prostate cancer. J Nat/ Cancer Inst 2002; 94: 1099-106.

12 Hellawell GO, Turner GD, Davies DR, Poulsom R, Brewster SF et al. Expression of the type 1 insulin-like growth factor receptor is up-regulated in primary prostate cancer and commonly persists in metastatic disease. Cancer Res 2002; 62: 2942-50.

13 Grimberg A. Mechanisms by which IGF-I may promote cancer. Cancer Biol Ther 2003; 2: 630-5.

14 Hellawell GO, Ferguson DJ, Brewster SF, Macaulay VM. Chemosensitization of human prostate cancer using antisense agents targeting the type 1 insulin-like growth factor receptor. BJU Int 2003; 91: 271-7.

15 Krueckl SL, Sikes RA, Edlund NM, Bell RH, Hurtado-Coll A et al. Increased insulinlike growth factor I receptor expression and signaling are components of androgenindependent progression in a lineage-derived prostate cancer progression model. Cancer Res 2004; 64: 8620-9.

16 Nickerson T, Chang F, Lorimer D, Smeekens SP, Sawyers CL et al. In vivo progression of LAPC-9 and LNCaP prostate cancer models to androgen independence is associated with increased expression of insulin-like growth factor I (IGF-I) and IGF-I receptor (IGF-IR). Cancer Res 2001; 61: 6276-80.

17 Cher ML, Bova GS, Moore DH, Small EJ, Carroll PR et al. Genetic alterations in untreated metastases and androgen-independent prostate cancer detected by comparative genomic hybridization and allelotyping. Cancer Res 1996; 56: $3091-$ 102.

18 Vocke CD, Pozzatti RO, Bostwick DG, Florence CD, Jennings SB et al. Analysis of 99 microdissected prostate carcinomas reveals a high frequency of allelic loss on chromosome 8p12-21. Cancer Res 1996; 56: 2411-6.

19 Dong JT. Chromosomal deletions and tumor suppressor genes in prostate cancer. Cancer Metastasis Rev 2001; 20: 173-93. Review.

20 Asatiani E, Huang WX, Wang A, Rodriguez Ortner E, Cavalli LR et al. Deletion, methylation, and expression of the NKX3.1 suppressor gene in primary human prostate cancer. Cancer Res 2005; 65: 1164-73.

21 He WW, Sciavolino PJ, Wing J, Augustus M, Hudson P et al. A novel human prostatespecific, androgen-regulated homeobox gene ( $N k \times 3.1)$ that maps to $8 \mathrm{p} 21$, a region frequently deletion in prostate cancer. Genomics 1997; 43: 69-77.

22 Zhang P, Liu W, Zhang J, Guan H, Chen W et al. Gene expression profiles in the PC-3 human prostate cancer cells induced by NKX3.1. Mol Biol Rep 2010; 37: 1505-12.

23 Pengju Z, Weiwen C, Aiying W, Zhaobo C, Nana N et al. NKX3.1 potentiates TNFalpha/CHX-induced apoptosis of prostate cancer cells through increasing caspase-3 expression and its activity. Biochem Biophys Res Commun 2010; 398: 457-61.

24 David S, Meinbach, Bal L, Lokeshwar. Insulin-like growth factors and their binding proteins in prostate cancer: cause or consequence? Urol Oncol 2006; 24: 294 306.

25 Chott A, Sun Z, Morganstern D, Pan J, Li T et al. Tyrosine kinases expressed in vivo by human prostate cancer bone marrow metastases and loss of the type 1 insulin-like growth factor receptor. Am J Pathol 1999; 155: 1271-9.

26 Burfeind P, Chernicky CL, Rininsland F, Ilan J. Antisense RNA to the type I insulin-like growth factor receptor suppresses tumor growth and prevents invasion by rat prostate cancer cells in vivo. Proc Natl Acad Sci USA 1996; 93: 7263-8.

27 David JS, Domenica G, Edward PG. DNA-binding sequence of the human prostatespecific homeodomain protein NKX3.1. Nucleic Acids Res 2000; 28: 2389-95. 
28 Vincent AM, Feldman EL. Control of cell survival by IGF signaling pathways. Growth Horm IGF Res 2002; 12: 193-7.

29 Rozengurt E. Convergent signaling in the action of integrin, neuropeptides, growth factors, and oncogenes. Cancer Surv 1995; 24: 81-96.

30 Buchwalter G, Gross C, Wasylyk B. Ets ternary complex transcription factors. Gene 2004; 324: 1-14. Review.

31 Yang SH, Sharrocks AD. Convergence of the SUMO and MAPK pathways on the ETSdomain transcription factor Elk-1. Biochem Soc Symp 2006; 73: 121-9. Review.
32 Shaw PE, Saxton J. Ternary complex factors: prime nuclear targets for mitogenactivated protein kinases. Int J Biochem Cell Biol 2003; 35: 1210-26. Review.

33 Butler AA, Blakesley VA, Poulaki V, Tsokos M, Wood TL et al. Stimulation of tumor growth by recombinant human insulin-like growth factor-I (IGF-I) is dependent on the dose and the level of IGF-I receptor expression. Cancer Res 1998; 58: 3021-7.

34 Wang P, Liu B, Luo JD, Zhang ZG, Ma Q et al. Expression of Nkx3.1 enhances 17 $\beta$ estradiol anti-tumor action in PC3 human prostate cancer cells. Asian J Androl 2007; 9: 353-60. 